Bull. Mater. Sci., Vol. 20. No. 8, December 1997, pp. 1089-1096. Printed in India.

\title{
Thermal behaviour of gel-grown pure and mixed rare earth tartrates of yttrium and samarium
}

\author{
ANIMA JAIN, SUSHMA BHAT, SANJAY PANDITA, \\ M L KAUL ${ }^{\dagger}$ and P N KOTRU* \\ Department of Physics, University of Jammu, Jammu 180004, India \\ 'Department of Chemistry, University of Jammu, Jammu 180004, India
}

MS received 18 July 1994; revised 16 September 1997

\begin{abstract}
Thermal behaviour of gel-grown pure and mixed rare earth tartrates of yttrium and samarium is investigated using thermogravimetric analysis (TGA) and differential scanning calorimetry (DSC). The thermal behaviour suggests that the materials are unstable at lower energies and pass through various stages of decomposition, decomposing to respective rare earth oxides which remain stable on further heating. It is estimated that both pure yttrium and pure samarium tartrate crystals carry eight waters of hydration, while mixed yttrium samarium tartrate crystals carry six waters of hydration. Critical examination of TG and DSC curves shows that the initial decompositions are endothermic and the latter are exothermic. Thermal kinetics of these materials has been worked out using Horowitz-Metzger, Piloyan-Novikova and Coats-Redfern equations. Application of these equations to these materials yields values of activation energy, order of reaction and frequency factor which are in reasonably good agreement.
\end{abstract}

Keywords. Yttrium samarium tartrate; thermal behaviour; solid state reaction kinetics.

\section{Introduction}

A large number of crystals obtained by low temperature solution techniques, using gel method, have been found to be thermally unstable even at moderate temperatures and the crystals which are thus obtained are associated with water of crystallization (Polla et al 1984; Kotru et al 1986a, b, c, 1987a, b; Mansotra et al 1991; Bhat and Kotru 1994, 1995). However, it is not so for materials grown using high temperature solution techniques. The thermogravimetric analysis of $\mathrm{CuWO}_{4}$ grown by indirect flux reaction technique reveals no weight loss and thus does not exhibit any phase transformations when heated to elevated temperatures (Arora et al 1988). However, we have observed weight losses at elevated temperatures in gel-grown materials, particularly rare earth tartrates and molybdates (Kotru et al 1986a, b, c, 1987a, b; Mansotra et al 1991; Bhat and Kotru 1994; Bhat et al 1995). Polla et al (1984) reported thermal studies of gel-grown bismuth oxalate, suggesting structural phase changes.

Tartrates find several practical applications in science and technology (Koisse 1974). As rare earth tartrates are practically insoluble in water and decompose at fairly low temperatures (Polla et al 1984; Kotru et al 1986a, b, c, 1987a, b; Mansotra et al 1991; Bhat and Kotru 1994; Bhat et al 1995), gel method is the appropriate one for their growth. This technique has been successfully employed for the growth of pure tartrates of $\mathrm{Y}, \mathrm{Sm}$ and mixed tartrates of $\mathrm{Y}$ and $\mathrm{Sm}$. The study of thermal behaviour is interesting and important.

We present the results of thermal analysis and reaction kinetics of single rare ( $\mathrm{Y}$ and $\mathrm{Sm})$ tartrates and mixed rare earth (Y:Sm) tartrates using TGA and DSC.

\footnotetext{
*Author for correspondence
} 


\section{Experimental}

The thermoanalytical studies, including thermogravimetric analysis (TGA) and differential scanning calorimetry (DSC) of pure and mixed rare earth tartrates $(R=Y, S m$, and $Y: S m$ ), were carried out using Swiss make Mettler thermal analyser TA3000. The content of water molecules in yttrium, samarium and yttrium samarium tartrates calculated from their respective thermograms is 8,8 and 6 respectively. For identifying the final product in the TG analysis $\mathrm{X}$-ray powder pattern of the end product obtained after heating the original compound to $840^{\circ} \mathrm{C}$ was recorded. DSC curves were obtained between $35^{\circ} \mathrm{C}$ and $500^{\circ} \mathrm{C}$ in ambient atmosphere at a heating rate of $10 \mathrm{~K} \mathrm{~min}^{-1}$ using baseline type 1 and plot mode 1 . Kinetic parameters like activation energy, order of reaction and frequency factor were determined from the thermograms.

\section{Results and discussion}

The growth of pure and mixed rare earth tartrates is accomplished using the system $\mathrm{R}\left(\mathrm{NO}_{3}\right)_{3}-\mathrm{Na}_{2} \mathrm{SiO}_{3}-\mathrm{C}_{4} \mathrm{H}_{6} \mathrm{O}_{6}(\mathrm{R}=\mathrm{Y}, \mathrm{Sm}$ and $\mathrm{Y}: \mathrm{Sm})$ (Jain et al 1991, 1996). Their thermal behaviour is as follows.

\subsection{Yttrium tartrate $\left[\mathrm{Y}_{2}\left(\mathrm{C}_{4} \mathrm{H}_{4} \mathrm{O}_{6}\right)_{3} \cdot 8 \mathrm{H}_{2} \mathrm{O}\right]$}

In the thermogravimetric analysis, weight of the sample taken was $14 \cdot 234 \mathrm{mg}$ and the heating rate was maintained at $10 \mathrm{~K} \mathrm{~min}^{-1}$ in air.
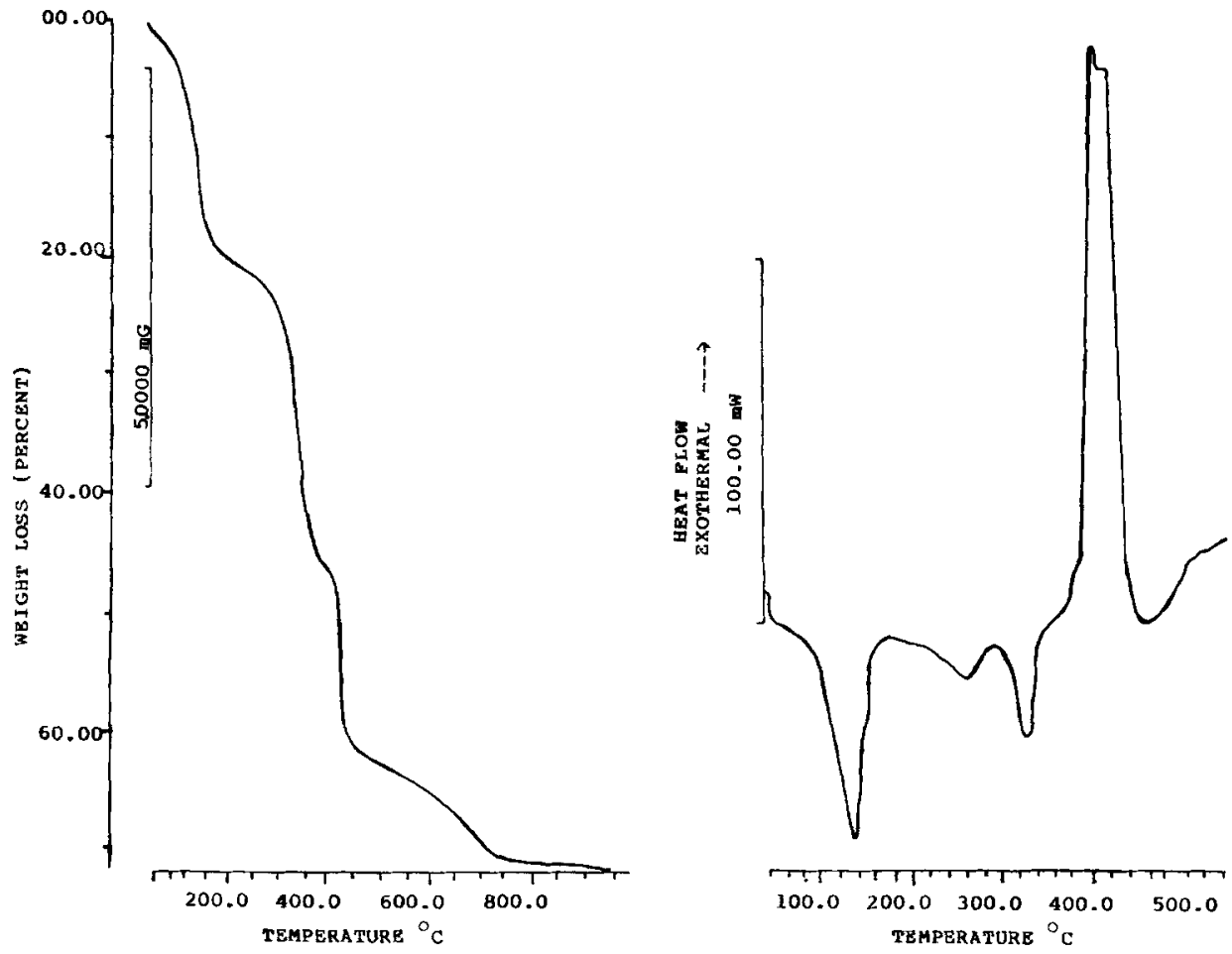

Figure 1. TG and DSC curves recorded for $\mathrm{Y}_{2}\left(\mathrm{C}_{4} \mathrm{H}_{4} \mathrm{O}_{6}\right)_{3} \cdot 8 \mathrm{H}_{2} \mathrm{O}$ crystals. 
Figure 1 shows the TG curve recorded for $\left[\mathrm{Y}_{2}\left(\mathrm{C}_{4} \mathrm{H}_{4} \mathrm{O}_{6}\right)_{3} \cdot 8 \mathrm{H}_{2} \mathrm{O}\right]$. Here the decomposition process starts at $45^{\circ} \mathrm{C}$. The first stage of decomposition continues up to $160^{\circ} \mathrm{C}$ leading to the formation of anhydrous yttrium tartrate which is stable up to $280^{\circ} \mathrm{C}$. The second stage of decomposition starts at $280^{\circ} \mathrm{C}$ and is completed at $340^{\circ} \mathrm{C}$, resulting in the formation of yttrium oxalate $\mathrm{Y}_{2}\left(\mathrm{C}_{2} \mathrm{O}_{4}\right)_{3}$ which remains stable up to $360^{\circ} \mathrm{C}$. In the third stage between $360-480^{\circ} \mathrm{C}$, oxalate of yttrium decomposes into basic carbonate i.e. $\mathrm{YO}\left(\mathrm{CO}_{3}\right)_{1 / 2}$ and finally in the fourth stage, basic carbonate gets reduced to oxide of yttrium $\left(\mathrm{Y}_{2} \mathrm{O}_{3}\right)$ which remains stable on further heating. Table 1 gives the summary of the decomposition steps and expected and observed mass loss percent at different steps for $\mathrm{Y}_{2}\left(\mathrm{C}_{4} \mathrm{H}_{4} \mathrm{O}_{6}\right)_{3} \cdot 8 \mathrm{H}_{2} \mathrm{O}$. Figure 1 also shows a DSC curve recorded for yttrium tartrate. Critical examination of the thermograms and the DSC curve indicates that all peaks in the DSC do not correspond to the mass changes in TG. The second DSC peak between $220-275^{\circ} \mathrm{C}$, i.e. before the second stage of decomposition, starts.

\subsection{Samarium tartrate $\left[\mathrm{Sm}_{2}\left(\mathrm{C}_{4} \mathrm{H}_{4} \mathrm{O}_{6}\right)_{3} \cdot 8 \mathrm{H}_{2} \mathrm{O}\right]$}

The weight of samarium tartrate in case of thermogravimetric analysis was taken as $12.675 \mathrm{mg}$ with the heating rate maintained at $10 \mathrm{~K} \mathrm{~min}^{-1}$.

Figure 2 gives the TG and DSC curves recorded for $\mathrm{Sm}_{2}\left(\mathrm{C}_{4} \mathrm{H}_{4} \mathrm{O}_{6}\right)_{3} \cdot 8 \mathrm{H}_{2} \mathrm{O}$. Critical examination of these curves (i.e. both TG and DSC) reveals that all transformations are associated with mass changes. Hence no physical transformation of the material is taking place. All changes in DSC correspond to the changes in TG. The results rule out the possibility of mere physical change in the crystallinity of the intermediates during the process of decomposition. The decomposition steps observed at different stages from the thermograms of figure 2 are summarized in table 1.

\subsection{Yttrium samarium tartrate $\left(\mathrm{Y}_{1 / 2} \mathrm{Sm}_{1 / 2}\right)_{2}\left(\mathrm{C}_{4} \mathrm{H}_{4} \mathrm{O}_{6}\right)_{3} \cdot 6 \mathrm{H}_{2} \mathrm{O}$}

Figure 3 shows TG and DSC curves recorded for the mixed rare earth (yttrium samarium tartrate). Here initial weight taken for recording the thermograms is $30.949 \mathrm{mg}$ and the heating rate is maintained at $10 \mathrm{~K} \mathrm{~min}^{-1}$. TG curve reveals that after an initial weight loss decomposition starts at $100^{\circ} \mathrm{C}$, while the DSC exhibits a peak at only $55^{\circ} \mathrm{C}$. This indicates that a phase change is taking place before the decomposition actually starts at $100^{\circ} \mathrm{C}$. Table 1 lists the summarized results of decomposition process of yttrium samarium tartrate. The first stage of decomposition continues up to $180^{\circ} \mathrm{C}$ where four water molecules are lost. The second stage between 200 and $240^{\circ} \mathrm{C}$ involves the elimination of the remaining (two) water molecules from the compound giving rise to anhydrous yttrium samarium tartrate which remains stable up to $260^{\circ} \mathrm{C}$ as seen in the TG curve of $260^{\circ} \mathrm{C}$ and is completed at $360^{\circ} \mathrm{C}$ leading to the formation of oxalate of the mixed compound $\left(\mathrm{Y}_{1 / 2} \mathrm{Sm}_{1 / 2}\right)_{2}\left(\mathrm{C}_{2} \mathrm{O}_{4}\right)_{3}$. This intermediate formation remains stable for only 9 degrees after which there appears to be another decomposition step $\left(369-579^{\circ} \mathrm{C}\right)$ leading to basic carbonate with observed mass loss of $55.55 \%$. It may be noted that since the stable state from $360^{\circ} \mathrm{C}$ onwards continues for short temperature interval of $9^{\circ} \mathrm{C}$ only, the intermediate step occurring after this stable state is not considered in the decomposition process discussed in table 1 . In the last stage between $600-760^{\circ} \mathrm{C}$ the oxalate further decomposes into oxide i.e. $\left(\mathrm{Y}_{1 / 2}: \mathrm{Sm}_{1 / 2}\right)_{2} \mathrm{O}_{3}$, as a final product remains stable on further heating. 


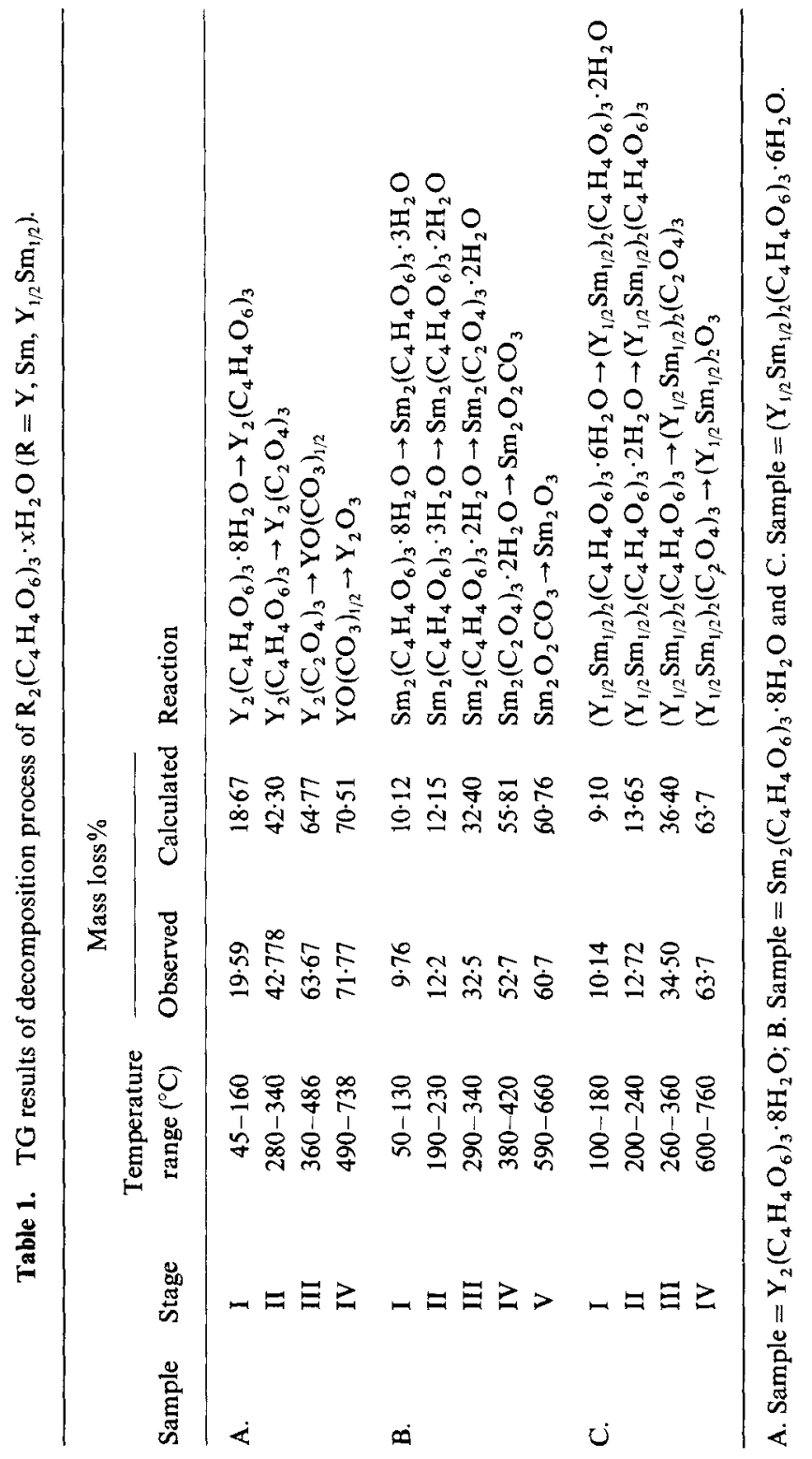



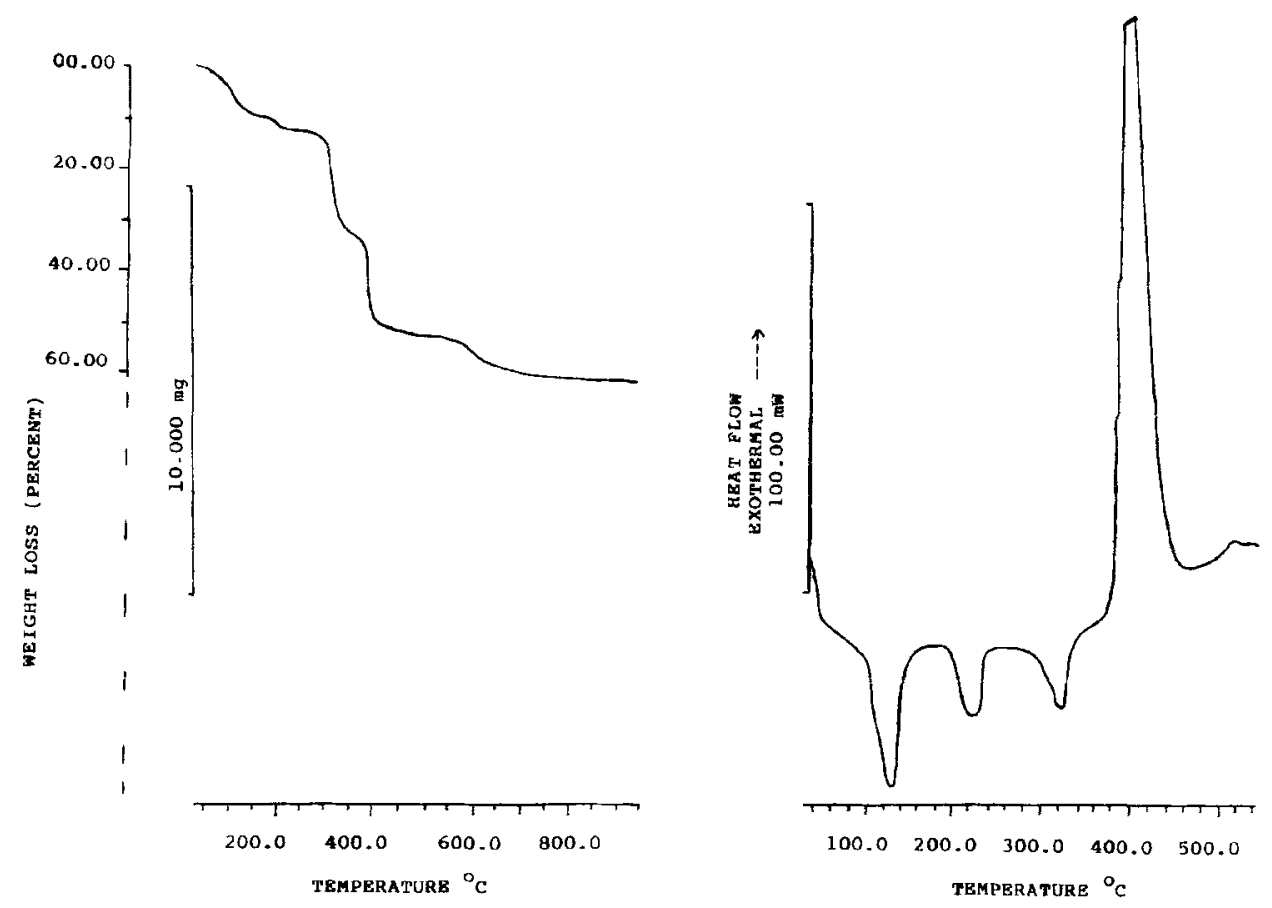

Figure 2. Thermograms showing TG and DSC curves of $\mathrm{Sm}_{2}\left(\mathrm{C}_{4} \mathrm{H}_{4} \mathrm{O}_{6}\right)_{3} \cdot 8 \mathrm{H}_{2} \mathrm{O}$.
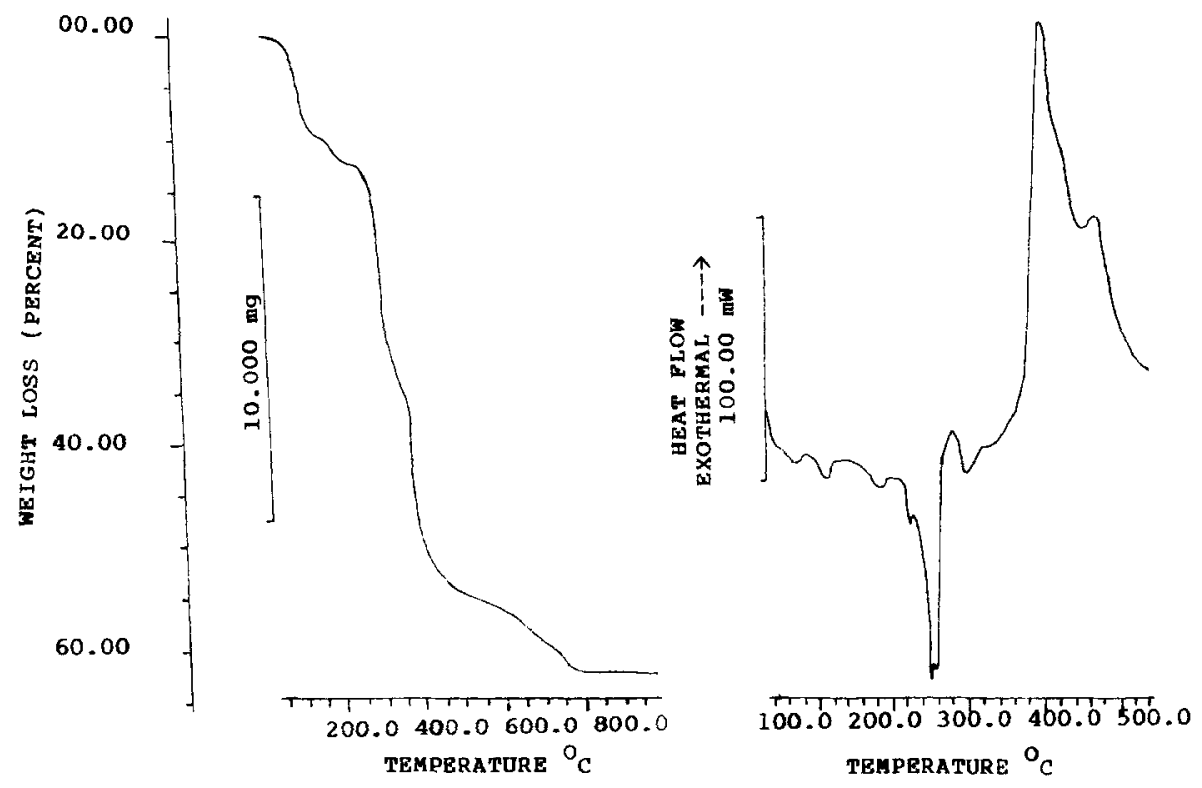

Figure 3. Thermograms showing TG and DSC curves of $\left(\mathrm{Y}_{1 / 2}: \mathrm{Sm}_{1 / 2}\right)_{2}\left(\mathrm{C}_{4} \mathrm{H}_{4} \mathrm{O}_{6}\right)_{3} \cdot 6 \mathrm{H}_{2} \mathrm{O}$.

The above-listed three DSC results suggest that the initial decompositions are endothermic while the latter decompositions at $340-500^{\circ} \mathrm{C}$ accompanied by oxidation of the decomposing products, are exothermic. These results are quite similar to those 
for other rare earth tartrates reported earlier by Kotru et al (1986a, b, c, 1987a, b) and Mansotra et al (1991). The decomposition pattern reported here is typical of a hydrated metal tartrate (Alfred et al 1970).

The energy required for dislodging water molecules depends on how strongly they are locked up in the lattice. It has been observed that some materials lose all waters of hydration in a single stage whereas in certain others they are ejected out from the lattice in different stages. It appears that all the water molecules in $Y$ tartrates unlike SmT and $\mathrm{Y}: \mathrm{SmT}$ were locked in a similar way and thus required same amount of energy for their ejection from the lattice.

\subsection{Thermal kinetics}

To know about the kinetics of solid state reactions leading to the decomposition of the materials, the equations of Horowitz-Metzger (1963), Piloyan-Novikova (1966), and Coats-Redfern (1964) were used for calculating the activation energy, order of reaction and frequency-factor for all the three compounds. The kinetics was studied for the first stage $\left(45-160^{\circ} \mathrm{C}\right.$ for $\mathrm{YT}, 50-130^{\circ} \mathrm{C}$ for $\mathrm{SmT}$ and $100-180^{\circ} \mathrm{C}$ for $\left.\mathrm{Y}: \mathrm{SmT}\right)$ of decomposition only, as in subsequent stages the sample characteristics could not be controlled. The relations used are given below:

1. Horowitz--Metzger relation:

$$
\log \left[\frac{1-(1-\alpha)^{1-n}}{1-n}\right]=E_{\theta} / 2 \cdot 303 R T_{\mathrm{m}}^{2},
$$

provided $n=1$, i.e. $n=1 / 2,1 / 4,2 / 3,1 / 3$.

$T-T_{\mathrm{m}}=\theta$, where $T$ is the temperature at a particular point of the curve and $T_{\mathrm{m}}$ the temperature of maximum reaction rate. The value of ' $\alpha$ ' is computed from the formula

$$
\alpha=\frac{\text { wt. loss up to a particular temperature }}{\text { total wt. loss in the step }}
$$

$R$ is the gas constant.

A plot of LHS, of the equation against $\theta$ shows a linear dependence from the slope of which activation energy, $E$ can be calculated.

2. Piloyan-Novikova relation:

$$
\log \left[\alpha / T^{2}\right]=\log (Z R / \beta E)-[E /(2 \cdot 303 R T)],
$$

where $\alpha=0.05$ to $0.5, \beta$ is the rate at which the temperature increases, $T$ the absolute temperature and $Z$ the frequency factor. The activation energy, $E$ can be calculated from the slope of a straight line obtained on plotting $\log \left(\alpha / T^{2}\right)$ against $1 / T$ and $Z$ from the intercept.

3. Coats-Redfern relation:

$$
\log \left[g(\alpha) / T^{2}\right]=\log [Z R / \beta E]-E / 2 \cdot 303 R T
$$

where $g(\alpha)$ turns out to be $2\left[1-(1-\alpha)^{1 / 2}\right]$.

The plot of LHS of the equation against $1 / T$ yields a straight line, the slope of which gives activation energy. The frequency factor is calculated from the intercept. 
Table 2. Energy of activation, order of reaction, frequency factor, calculated from 1st stage of decomposition of $\mathrm{R}_{2}\left(\mathrm{C}_{4} \mathrm{H}_{4} \mathrm{O}_{6}\right)_{3} \cdot x \mathrm{H}_{2} \mathrm{O} ; \mathrm{R}=\mathrm{Y}, \mathrm{Sm}, \mathrm{Y}: \mathrm{Sm}$.

\begin{tabular}{|c|c|c|c|c|}
\hline Sample & Relation used & $\begin{array}{c}\text { Order of } \\
\text { reaction }(n)\end{array}$ & $\begin{array}{c}\text { Frequency } \\
\text { factor }(z)\end{array}$ & $\begin{array}{l}\text { Energy of activation } \\
\qquad(E) \mathrm{Kcal} / \mathrm{mol}\end{array}$ \\
\hline \multirow[t]{3}{*}{$\mathrm{Y}_{2}\left(\mathrm{C}_{4} \mathrm{H}_{4} \mathrm{O}_{6}\right)_{3} \cdot 8 \mathrm{H}_{2} \mathrm{O}$} & $\mathrm{H}-\mathrm{M}$ & $1 / 2$ & - & $14 \cdot 74$ \\
\hline & $\mathrm{P}-\mathrm{N}$ & $1 / 2$ & $14.57 \times 10^{4}$ & $9 \cdot 17$ \\
\hline & $C-R$ & $1 / 2$ & $9.23 \times 10^{4}$ & 11.60 \\
\hline \multirow[t]{3}{*}{$\mathrm{Sm}_{2}\left(\mathrm{C}_{4} \mathrm{H}_{4} \mathrm{O}_{6}\right)_{3} \cdot 8 \mathrm{H}_{2} \mathrm{O}$} & $\mathrm{H}-\mathrm{M}$ & $1 / 2$ & $\cdots$ & 12.63 \\
\hline & $\mathrm{P}-\mathrm{N}$ & - & $12.65 \times 10^{4}$ & 9.96 \\
\hline & $C-\mathbf{R}$ & $1 / 2$ & $5.97 \times 10^{4}$ & 8.91 \\
\hline \multirow[t]{3}{*}{$\left(\mathrm{Y}_{1 / 2} \mathrm{Sm}_{1 / 2}\right)_{2}\left(\mathrm{C}_{4} \mathrm{H}_{4} \mathrm{O}_{6}\right)_{3} \cdot 6 \mathrm{H}_{2} \mathrm{O}$} & $\mathrm{H}-\mathrm{M}$ & $1 / 2$ & - & - \\
\hline & $\mathrm{P}-\mathrm{N}$ & -- & $6.17 \times 10^{7}$ & 15.47 \\
\hline & $C-R$ & $1 / 2$ & $2.59 \times 10^{7}$ & 14.51 \\
\hline
\end{tabular}

Table 2 gives values of activation energy, order of reaction and frequency factor for first stage of decomposition in case of yttrium, samarium and yttrium samarium tartrates. The first stage of decomposition is similar in each compound viz. total or partial dehydration. This is important for comparison purposes. This procedure has been followed in our earlier publications (Kotru et al 1986a, b, c, 1987a, b; Bhat et al 1995) and has also been accepted by others (Young 1966).

For solid state reactions, different models have been proposed depending on the type of processes leading to the reactions (Sestak 1971). In the present cases, the application of $\mathbf{H}-\mathbf{M}$ and $\mathrm{C}-\mathrm{R}$ relations suggests a contracting cylinder kinetic model as an appropriate one for the mechanism of decomposition. In the former case, the relation leads to a good linear fit with $f(\alpha)=\left[(1-\alpha)^{1 / 2}\right]$, while in the latter case, best linear fit is obtained with $g(\alpha)=2\left[1-(1-\alpha)^{1 / 2}\right]$. The average values as calculated on application of three kinetic equations may be taken as approximately $8.498 \mathrm{kcal} / \mathrm{mol}$ for YT, $10.499 \mathrm{kcal} / \mathrm{mol}$ for $S \mathrm{mT}$ and $14.989 \mathrm{kcal} / \mathrm{mol}$ for $\mathrm{Y}: S m T$.

The results of thermal kinetics in case of pure rare earth tartrates of $Y, S m$ and mixed rare earth tartrate of $\mathrm{Y}-\mathrm{Sm}$ are in agreement with those of other rare earth tartrates reported earlier by Kotru et al (1986a, b, c, 1987a, b), thereby suggesting a contracting cylinder kinetic model as a relevant one for explaining the results of thermal decomposition in case of the rare earth tartrates.

\section{Conclusions}

(I) The content of water molecules in yttrium, samarium and yttrium samarium tartrates is 8,8 and 6 respectively, thus assigning the following formulae to them; $\mathrm{Y}_{2}\left(\mathrm{C}_{4} \mathrm{H}_{4} \mathrm{O}_{6}\right)_{3} \cdot 8 \mathrm{H}_{2} \mathrm{O}, \mathrm{Sm}_{2}\left(\mathrm{C}_{4} \mathrm{H}_{4} \mathrm{O}_{6}\right)_{3} \cdot 8 \mathrm{H}_{2} \mathrm{O}$ and $\left(\mathrm{Y}_{1 / 2} \mathrm{Sm}_{1 / 2}\right)_{2}\left(\mathrm{C}_{4} \mathrm{H}_{4} \mathrm{O}_{6}\right)_{3} \cdot 6 \mathrm{H}_{2} \mathrm{O}$.

(II) The thermal behaviour of the three compounds suggests the materials to be unstable even at lower energies. All transformations taking place at elevated temperatures are associated with mass changes, ruling out the possibility of mere physical changes in the crystallinity of the intermediates, during the process of decomposition. 
(III) The application of Horowitz-Metzger, Piloyan-Novikova and Coats-Redfern relations yield values which are in reasonably good agreement. The results suggest a contracting cylinder kinetic model as the one that could explain the results of thermal decomposition of pure rare earth tartrates including $\mathrm{Y}_{2}\left(\mathrm{C}_{4} \mathrm{H}_{4} \mathrm{O}_{6}\right)_{3} \cdot 8 \mathrm{H}_{2} \mathrm{O}, \mathrm{Sm}_{2}$ $\left(\mathrm{C}_{4} \mathrm{H}_{4} \mathrm{O}_{6}\right)_{3} \cdot 8 \mathrm{H}_{2} \mathrm{O}$ and mixed rare earth $(\mathrm{Y}, \mathrm{Sm})$ tartrates $\left(\mathrm{Y}_{1 / 2}, \mathrm{Sm}_{1 / 2}\right)_{2}\left(\mathrm{C}_{4} \mathrm{H}_{4} \mathrm{O}_{6}\right)_{3} \cdot 6 \mathrm{H}_{2} \mathrm{O}$.

\section{References}

Alfred C, Latz G, Litnant I and Rubin B 1970 Proc. symp. on analytical calorimetry, Chicago, in Analytical calorimetry (New York: Plenum Press) vol. 2 p. 255

Arora S K, Mathew Thomas and Batra N M 1988 J. Cryst. Growth 88379

Bhat Sushma and Kotru P N 1994 Mater. Chem. Phys. 39118

Bhat Sushma and Kotru P N 1995 J. Mater. Sci. \& Technol. 1141

Bhat Sushma, Kotru P N and Koul M L 1995 J. Mater. Sci. \& Technol. 11455

Coats A W and Redfern J P 1964 Nature (GB) 20168

Horowitz H H and Metzger G 1963 Anal. Chem. 351464

Jain Anima, Razdan Ashok and Kotru P N 1991 Mater. Sci. \& Engg. B8 129

Jain Anima, Kotru P N and Koul M L 1996 J. Mater. Sci. \& Technol. 1281

Koisse F G A 1974 in Crystal structure of inorganic compounds (ed) T I Malinowskii (Kishneve: Shtuntza Press) p. 103

Kotru P N, Gupta N K, Raina K K and Koul M L 1986a Bull. Mater. Sci. 8547

Kotru P N, Gupta N K, Raina K K and Sharma I B 1986b J. Mater. Sci. 2183

Kotru P N, Raina K K and Koul M L 1986c J. Mater. Sci. 213933

Kotru P N, Raina K K and Koul M L 1987a Indian J. Pure \& Appl. Phys. 25220

Kotru P N, Raina K K and Koul M L 1987b J. Mater. Sci. Lett. 6711

Mansotra V, Raina K K, Kotru P N and Koul M L 1991 J. Mater. Sci. 266729

Piloyan G O and Novikova D S 1966 Inorg. Chem. (USSR) 12313

Polla G, Bagio R F, Manghi E and dePererzzo P K 1984 J. Cryst. Growth 8768

Sestak 1971 in Thermal analysis, Proc. of the 3rd international conference on thermal analysis (ed) Wiedmann Vol. 2 p. 24

Young D A 1966 in International encyclopaedia of physical chemistry, solid and surface kinetics (ed) F C Tompkins (London: Pergamon Press) p. 68 